\title{
Hepatoprotective Effect of Garlic Homogenate Co-Administered with Anti-Tuberculosis Drugs in Rat Liver Enzymes
}

\author{
Nasiru A., Hafsat. I. G., Mohammad M. M., and Sabo A. A.
}

\begin{abstract}
The aim of this work is to evaluate the hepatoprotective effect of garlic homogenate co-administered with anti-tuberculosis drugs on the liver. Twenty rats were divided into five groups (each of four rats) designated A, B, C, D and $E$ (control). $51.4 \mathrm{mg} / \mathrm{kg}$ body weight of first line tuberculosis drugs (Isoniazid, Rifampicin, Pyrazinamide and ethambutol) was administered orally to two (2) rats in group A, B, C, and D for seven (7) days and the remaining two rats in each group for twenty-eight (28) days. $28.5 \mathrm{mg} / \mathrm{kg}, 42.8 \mathrm{mg} / \mathrm{kg}$ and $57.1 \mathrm{mg} / \mathrm{kg}$ body weight of the garlic were co-administered with the anti-tuberculosis drugs to group (B), (C) and (D) respectively. Group (A) serve as negative control. From the results obtained, it was observed that the values of AST, ALT and ALP were significantly higher in rats administered with $51.4 \mathrm{mg} / \mathrm{kg}$ of first line anti -TB drugs (negative control) when compared with rats co-administered with same anti-TB drugs and $57.1 \mathrm{mg} / \mathrm{kg}$ of garlic homogenate. $(P<0.05)$. The AST and ALT levels were found to increase progressively as garlic concentration decreases. This result has also showed that anti-tuberculosis drugs are hepatotoxic from the values (AST: $47.5 \pm 3.53$, ALP: 87.0 \pm 4.24 and $A L T: 52.0 \pm 4.24)$ obtained in group $A$ (negative control) when compared to group $E$ (positive control) values (AST: $10 \pm 1.41$, ALP: $33 \pm 4.24$ and ALT: $10 \pm 4.24$ ). There were no significance differences obtained in the level of AST and ALT when compared with seven (7) days treatment. Histological test was done to confirm the results obtained. From this work it can be suggested that supplementation of garlic in individuals on first line anti-TB drugs may be beneficial as garlic proves to be hepatoprotective. The hepatoprotective effect of garlic is dose dependent.
\end{abstract}

Index Terms-Alanine transaminase (ALT), alkaline phosphatase (ALP), aspartate transaminase (AST), tuberculosis (TB).

\section{INTRODUCTION}

Tuberculosis is a common and in many cases lethal infectious disease cause by various strain of mycobacterium tuberculosis [1]. It is spread through the air by cough, sneeze or contact with saliva [2]. Inhaling fewer than ten bacteria may cause an infection [3]. It is estimated that approximately one third of the worlds is infected with mycobacterium tuberculosis with 8.8 million new cases during 2005 alone [4] The number of new cases is increasing worldwide [5]. 80\% of populations in many Asia and Africa countries are positive to the tuberculin tests [1]. About 1.6 million people died from Tuberculosis (TB) in 2005 [4]. In Northern part of Nigeria If tuberculosis is left untreated; around half of those with active

Manuscript received August 8, 2012; revised September 17, 2012.

The authors are with the Department of Biochemistry, Faculty of Science, Bayero University Kano, Nigeria (e-mail: nasiruabdullahi@yahoo.com). tuberculosis will die of the disease [6]. The number of TB cases throughout the world has been increasing rapidly due to the emergence of Multi Drug Resistance TB (MDR-TB) [7]. Drugs used for the treatment of TB includes isoniazid(INH), rifampicin (RPM), ethambutol (EMB) and streptomycin (ISM) [8].These drugs are considered as first line anti-TB drugs. Closerine, pyrazinamide and ethionamide are given as a second line of defence against resistant strain bacteria, although they are more toxic and less effective [8]. The frequency and severity of hepatotoxicity is increased when these drugs are used in combination [9]. A meta analysis of studies involving several anti tuberculosis drug regiments estimates the incidence of liver toxicity to be $2.6 \%$ with co-administered isoniazid and rifampicin, $1.6 \%$ with isoniazid alone, and $1.1 \%$ with rifampicin alone [10]. Antituberculosis drugs cause liver membrane damage leading to leakage of ALT, AST, ALP, and Billirubin [11]. In another study pyrazinamide causes more hepatotoxicity than isoniazid or rifampicin [12]. No new drugs have been developed for many years as such there is the urgent need to search for a new effective and affordable anti-TB drugs. [13]

Effective nutritional/herbal formular may support $\mathrm{TB}$ treatment in individuals with tuberculosis. Garlic (Allum Sativum), specie of the onion genus is one of the most popular herbs used worldwide. The steroids, terpenoids, flavonoids and other phenols have increasingly been identified as possible active ingredients in garlic [14]. Consumption of a flavonoid rich diet might decrease the risk of degenerative changes in certain diseases. [15]. Allum Sativum has been found to reduce hyperlipidemia [16]. Reference [17] reported that garlic supplementation significantly reduce aortic plaque deposits of cholesterol fed rabbits. Aged garlic extract and its constituent have been shown to inhibit $\mathrm{cu}^{2+}$ induced oxidative modification of low-density lipoprotein [18]. The mechanistic action of garlic might be due to organosulphur compound in it [19]. Activity of ALT and AST are sensitive markers of acute hepatic necrosis, and ALP level is an indicative marker of hepatobilliary disease. [20].The aim of this research is therefore to determine the hepatoprotective effect of garlic on liver by monitoring the levels of ALT, AST and ALP.

\section{Methods}

\section{A. Experimental Design}

Twenty rats were divided into five groups each of four rats designated A,B,C,D and E (control). $51.4 \mathrm{mg} / \mathrm{kg}$ body weight of tuberculosis drug solution was administered orally to two 
(2) rats in group A,B,C, and D for seven(7) days and the remaining two rats in each group for twenty-eight (28) days. Garlic extract of $28.5 \mathrm{mg} / \mathrm{kg}, 42.8 \mathrm{mg} / \mathrm{kg}$ and $57.1 \mathrm{mg} / \mathrm{kg}$ body weight were co-administered with first line of anti tuberculosis drugs to group B, C and D respectively. Group A serve as negative control. A section of the liver tissue was collected from each group for histological analysis.

\section{B. Biochemical Analysis}

Serum ALP was determined as outlined by [21], while ALT and AST were determined using [22] methods.

\section{Preparation of Garlic Homogenate}

$50 \mathrm{mg} / \mathrm{ml}$ of freshly prepared garlic homogenate was prepared by diluting $5 \mathrm{~g}$ of blended garlic with $100 \mathrm{ml}$ of distilled water.

\section{Preparation of Anti-Tuberculosis Drug}

$20 \mathrm{mg} / \mathrm{ml}$ of first line anti-tuberculosis drug solution was prepared by dissolving $2 \mathrm{~g}$ of anti-tuberculosis drugs in $100 \mathrm{ml}$ of distilled water.

\section{E. Histological Analysis}

The liver biopsy was fixed with $10 \%$ formal saline dehydrated with ascending grade of alcohol cleared with molten paraffin wax. The tissue sections were cut with microton and stained with haematoxylin and eosin staining techniques.

\section{F. Statistical Analysis}

The student t-test was used and value of $P<0.05$ is significant

\section{RESULTS}

\section{A. Tables}

TABLE I: MEAN SERUM AST, ALP AND ALT ACTIVITIES ANALYZED IN EXPERIMENTAL RATS INDUCED WITH ANTI-TUBERCULOSIS DRUGS CO-ADMINISTERED WITH GARLIC EXTRACT FOR SEVEN (7) DAYS.

\begin{tabular}{|c|c|c|c|}
\hline Groups & $\overline{\text { AST (U/L) }}$ & $\mathbf{A L P}(\mathbf{U} / \mathrm{L})$ & $\operatorname{ALT}(\mathbf{U} / \mathbf{L})$ \\
\hline $\begin{array}{l}\text { Group A } \\
\text { (negative } \\
\text { control } \\
\text { Anti-TB drug } \\
\text { only) }\end{array}$ & $47.5 \pm 3.53$ & $\begin{array}{l}87.1 \pm \\
4.24\end{array}$ & $52.0 \pm 4.24$ \\
\hline $\begin{array}{l}\text { Group B } \\
\text { (Anti-TB } \\
+28.5 \mathrm{mg} / \mathrm{kg} \text { of } \\
\text { Garlic) }\end{array}$ & $41.0 \pm 1.41$ & $84.0 \pm 5.65$ & $43.5 \pm 2.12$ \\
\hline $\begin{array}{l}\text { Group C } \\
\text { (Anti-TB + } \\
42.8 \mathrm{mg} / \mathrm{kg} \text { of } \\
\text { Garlic) }\end{array}$ & $32.5 \pm 4.94$ & $85.0 \pm 1.41$ & $40.5 \pm 3.52$ \\
\hline $\begin{array}{l}\text { Group D } \\
\text { (Anti-TB } \\
+\mathbf{5 7 . 1 m g / k g ~ o f ~} \\
\text { Garlic) }\end{array}$ & $24.5 \pm 2.12$ & $66.0 \pm 5.65$ & $25.5 \pm 4.94$ \\
\hline $\begin{array}{l}\text { Group E } \\
\text { (positive } \\
\text { control) }\end{array}$ & $10.0 \pm 1.41$ & $33 \pm 4.24$ & $10 \pm 4.24$ \\
\hline
\end{tabular}

Values are represented as mean \pm standard deviation
TABLE II: MEAN SERUM AST, ALP AND ALT ACTIVITIES ANALYZED IN EXPERIMENTAL RATS INDUCED WITH ANTI-TUBERCULOSIS DRUG CO-ADMINISTERED WITH GARLIC EXTRACT FOR TWENTY-EIGHT (28) DAYS.

\begin{tabular}{llll}
\hline Groups & AST (U/L) & ALP (U/L) & ALT (U/L) \\
\hline $\begin{array}{l}\text { Group A } \\
\text { (negative }\end{array}$ & $67.5 \pm 3.53$ & $106.5 \pm 6.36$ & $61.5 \pm 2.12$ \\
control : \\
Anti-TB drug \\
only)
\end{tabular}

Values are represented as mean \pm standard deviation.

\section{B. Figures}

Histology Results Fig. 1

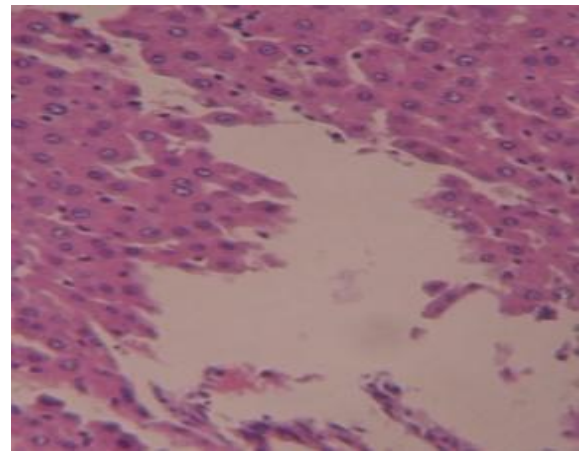

Fig. 1. Negative control.

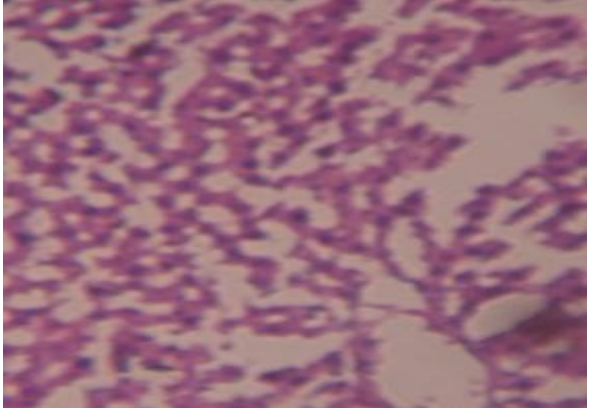

Fig. 2. Group B.

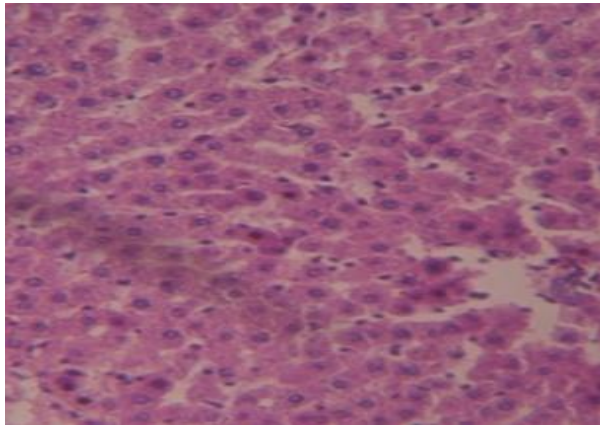

Fig. 3. Group C. 


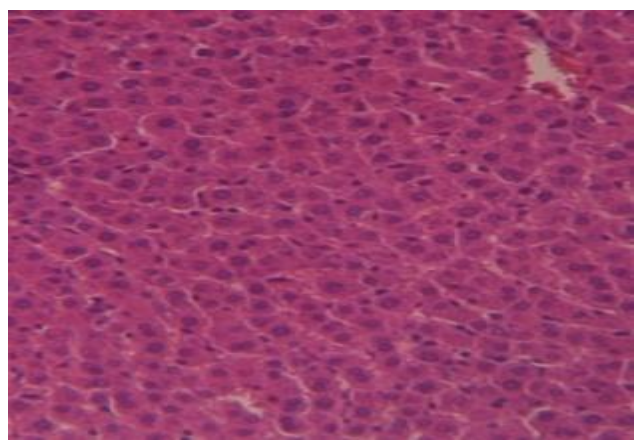

Fig. 4. Group D.

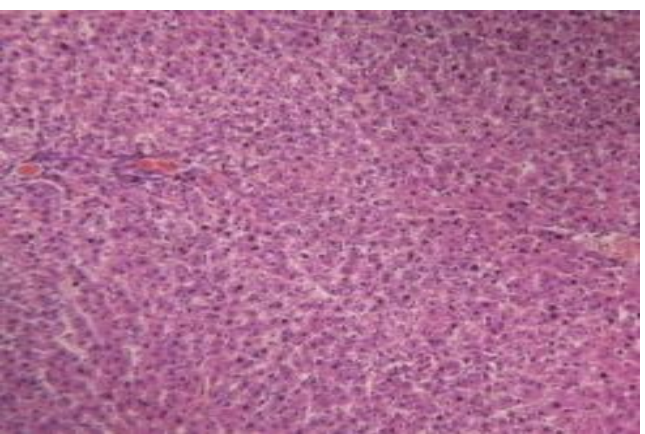

Fig. 5. Positive control

\section{DISCUSSION}

From the results obtained in this work, it was observed that the values of AST, ALT and ALP were significantly higher in rats administered with $51.4 \mathrm{mg} / \mathrm{kg}$ first line anti - TB drugs (negative control) when compared with rats co-administered with same anti-TB drugs and $57.1 \mathrm{mg} / \mathrm{kg}$ of garlic extract. $(P<0.05)$. The AST and ALT levels were found to increase progressively as garlic concentration decreases (Table I). A recent study have shown that the co-treatment of anti-tuberculosis drug with onion extract, prevent hepatotoxicity of the drugs in rats and the enzyme markers were kept in a normal level [23]. This result has also showed that anti-tuberculosis drugs are hepatotoxic, with values (AST: $47.5 \pm 3.53$, ALP: $87.0 \pm 4.24$ and ALT: $52.0 \pm 4.24$ ) obtained in group A (negative control), when compared with group E (positive control) values (AST: $10 \pm 1.41$, ALP: $33 \pm$ 4.24 and ALT: $10 \pm 4.24)$. This conforms to the findings in [10] on the hepatotoxicity of anti- tuberculosis drugs. The anti-tuberculosis drugs may have induced peroxidative damage resulting to the higher levels of the liver enzymes assayed [24]. Anti-tuberculosis drugs act as inducers of hepatic cytochrome P450 enzymes [25]. The Inhibition of P450 enzymes has been shown to be hepatoprotective [26]. When the rats were subjected to twenty-eight (28) days similar treatment as in table I, the negative control value of AST, ALP and ALT were all higher than the seven (7) days treatment. These therefore suggest the further damage to the liver. On the effect of the anti-tuberculosis drugs co-administered for twenty-eight (28) days, there were no significance difference obtained in the level of AST and ALT when compared with seven (7) days treatment. The Histology results confirms the extent of the liver damage by anti-TB drugs as seen from the scan of the negative control fig. 1, the size of the grey areas indicates the extent of liver damage which was absent in the group treated with $57.1 \mathrm{mg} / \mathrm{kg}$ of garlic extracts fig. 4. Oxidative Stress has been linked with isoniazid administration in rats, as reduce levels of glutathione S-transferase, catalase and superoxide dismutase were obtained [27]. The Histology results conforms with these findings as it can be seen that the Negative Control fig. 1 shows signs of oxidative stress due to the combine effect of the first line anti-TB drugs administered. Fig. 2-4 shows decrease in the grey areas as the concentration of garlic increases, from this research it can be suggested that supplementation of garlic in individuals on anti-TB drugs may be beneficial, as garlic proves to be hepatoprotective. Co-administration of garlic may have played a role in reducing the effect of oxidative stress in group $\mathrm{B}, \mathrm{C}$ and $\mathrm{D}$ Fig. 2-4. Available literatures have shown that extracts obtained from several plants have hepatoprotective activities against the toxicity induced by xenobiotics, including those that are used in the treatment of tuberculosis [28]. The result obtained in this work indicates that the hepatoprotective effect of garlic is dose dependent but not on the duration of garlic intake.

\section{CONCLUSION AND RECOMMENDATIONS}

It can be concluded that garlic has hepatoprotective effect against anti-tuberculosis drugs in rats. The use of patient with tuberculosis is strongly recommended to ascertain the protective effect of garlic. Assessment of other species of onion might also be helpful towards the management of the toxic effects of the drugs. Further investigation on Curative effect of some plants should also be done as it may pave way for new drugs development. It is finally hoped that nutritional supplementation for those with tuberculosis may be beneficial.

\section{REFERENCES}

[1] V. Kumar, A. K. Abbas, N. Fausto, and R. N. Mitchell, Robins Basic Pathology, $8^{\text {th }}$ ed . Saunders Elsevier, 2007, pp. 516-522.

[2] A. Constantinos, "Testing for tuberculosis," Australian Prescriber, vol. 33, no. 1, pp. 12-18, 2010.

[3] M. Nicas, W. W. Nazaroff, and A. Hubbard, "Toward understanding the risk of secondary airborne infection: emission of respirable pa thogens,' J. Occup Environ Hyg., vol. 2, no. 3, pp. 143-54, 2005.

[4] World Health Organisation (WHO), "Global tuberculosis control: Surveillance, planning and financing," WHO Report Genev, 2006.

[5] World Health Organisation (WHO), "The stop TB strategy, case, reports, treatment outcomes and estimates of TB burden. Global tuberculosis control- surveilance, planning and financing," WHO Report, 2009.

[6] E. L, Corbet, C. J. Watt, N. Walker, D. Maher, B. G. Williams, and M C. Raviglione, "The growing burden of tuberculosis: Global trends and interactions with HIV epidemic,' Archives of Internal Medicine, vol. 163, no. 9, pp. 1009-1021, 2003.

[7] E. D Chan and M. D. Iseman, "Current medical treatment for tuberculosis,” Br. Med. J. vol. 325, pp. 1282-1286, 2002.

[8] J. D. Ernst, G. T. Nunez, and N. Banaiee, "Genomics and the evolution, pathogenesis, and diagnosis of tuberculosis," J. Clin. Invest, vol. 117 no. 7, 2007.

[9] A. Trevor, B. Katzung, and S. Masters, Katzung and Trevor's Pharmacology, McGraw-Hill, 2004.

[10] M. A Steele, R. F. Burk, and R. M. Desprez, "Toxic hepatitis with isoniazid and rifampicin," A Meta Analysis, Chest vol. 99, pp. 465-471, 1991

[11] S. A. Tasaduq, P. Kaiser, S. C. Sharma, and R. K. Johri, "Potentiation of isoniazid induced liver toxicity by rifampicin in a combination therapy of antitubercular drugs (rifampicin, isoniazid and pyrazinamide) in Wistar rats," Hepatol Res, vol. 37, pp. 845-853, 2007.

[12] D. Yee , C. Valiquette, M. Pelletier, I. Parisien, I. Rocher, and D. Menzies, "Incidence of serious side effects from first-line 
antituberculosis drugs among patients treated for active tuberculosis,' Am. J. Respir. Crit Care Med, vol. 167, pp. 1472-1477, 2003.

[13] R. Gautam, A. Saklani, and S. M. Jachak, "Indian medicinal plants as a source of antimycobacterial agents," Journal of Ethnopharmacology, vol. 110, pp. 200-234, 2007.

[14] K. Agarwal, "Therapeutic actions of garlic constituents," Medicinal Res Rev, vol. 16, no. 1, pp. 111-124, 1996.

[15] K. Nemeth and M.K. Piskula, "Food content, processing, absorption and metabolism of onion flavonoids," Crit Rev, Food Sci Nutr, vol. 47, pp. 397-409, 2007.

[16] J. Kojuri, A. R. Vosoughi, and M. Akrami, "Effect of anethum graveolens and garlic on lipid profile in hyperlipidemic patients,' Lipids Health Dis, vol. 1, no. 6, pp. 5, 2007.

[17] I. Durak, H. S. Ozturk, E. Olcay, and C. Guven, "Effects of garlic extract supplementation on blood lipid and antioxidant parameters and atherosclerotic plaque formation process in cholesterol-fed rabbits," $J$ herb Pharmacother, vol. 2, no. 2, pp. 19-32, 2002.

[18] N. Ide and B. H. Lau, "Garlic compounds protect vascular endothelial cells from oxidized low density lipoprotein-induced injury," J. Pharm Pharmacol, vol. 49, no. 9, pp. 908-911, 1997.

[19] C. Devived, L. M. John, and D. S. Schmidt, "Effect of oil soluble organosulfur compounds from garlic on doxorubicin-induced lipid peroxidation," Anticancer Drugs, vol. 9, no. 3, pp. 291-294, 1998.

[20] G. Schumann, R. Bonora, and F. Ceriotti, "IFCC Primary reference procedure for the measurement of catalytic concentration of aspartate aminotransferase," Clin Chem Lab Med, vol. 40, pp.725-733, 2002.

[21] E. J. King and A. R. Armstrong, "Determination of serum alkaline phosphatase activity," Canadian Medical Journal, vol. 31, pp. 376 1964.
[22] S. Reitman and S. Frankel, "A colorimetric method for the determination of glutamic oxaloacetate and glutamate transaminase," Journal of Clin Pharmacology, American, vol. 28, pp. 56, 1957.

[23] T. Sana, I. Javed and A. Aamir, "Antituberculous treatment induced ALT and ALP derangements and the role of onion extract in male albino Rats," A. P. M. C, vol. 4, no. 1, pp. 33, 2010.

[24] S. Santosh, T. K. Sini, R. Anandan, and P. T. Mathew, "Effect of chitosan supplementation on antitubercular drugs induced hepatotoxicity in rats," Toxicology, vol. 219, pp. 53-59, 2000.

[25] N. Vuilleumier, M. F. Rossier, A. Chiappe, F. Degoumois, P. Dayer, B. Mermillod, L. Nicod, J. J. Desmeules, and D. Hochstrasser., "CYP2E1 genotype and isoniazid-induced hepatotoxicity in patient treated for latent tuberculosis," Eur J Clin Pharmacol., vol. 62, pp. 423-429, 2006

[26] B. U. Bradford, H. Kono, F. Isayama, O. Kosyk, M. D. Wheeler, T. E. Akiyama, L. Bleye, K. W. Krausz, F. J. Gonzalez, D. R. Koop, and I Rusyn, "Cytohcrome P450 CYP2E1, but not adenine dinucleotide phosphate oxidase, is required for-ethanol-induced oxidative DNA damage in rodent liver," Hepatology, vol. 41, pp. 336-344, 2005.

[27] A. Chowdhury, A. Santra, S. Kundu, et al., "Induction of oxidative stress in antitubercular drug-induced hepatotoxicity," J. Gastroenterol, Indian, vol. 20, no. 97-100, 2001.

[28] S. A. Tasduq, K. Singh, N. K. Satti, D. K. Gupta, K. A. Suri, and R. K Johri, "Terminalia chebula (fruit) prevents liver toxicity caused by sub-chronic administration of rifampicin, isoniazid and pyrazinamide in combination," Hum Exp Toxicol., vol. 25, pp. 111-118, 2006. 